\title{
ON THE FEKETE-SZEGÖ PROBLEM
}

\section{B. A. FRASIN and MASLINA DARUS}

(Received 9 May 2000)

ABSTRACT. Let $f(z)=z+a_{2} z^{2}+a_{3} z^{3}+\cdots$ be an analytic function in the open unit disk. A sharp upper bound is obtained for $\left|a_{3}-\mu a_{2}^{2}\right|$ by using the classes of strongly starlike functions of order $\beta$ and type $\alpha$ when $\mu \geq 1$.

Keywords and phrases. Univalent and analytic functions, starlike and convex functions, Fekete-Szegö problem.

2000 Mathematics Subject Classification. Primary 30C45.

1. Introduction. Let $\mathscr{A}$ denote the family of functions of the form

$$
f(z)=z+\sum_{n=2}^{\infty} a_{n} z^{n}
$$

which are analytic in the open unit disk $U=\{z:|z|<1\}$. Further, let $\mathscr{Y}$ denote the class of functions which are univalent in $\mathcal{U}$. A function $f(z)$ belonging to $\mathscr{A}$ is said to be strongly starlike of order $\beta$ and type $\alpha$ in $U$, and denoted by $\overline{\mathscr{T}}_{\alpha}^{*}(\beta)$ if it satisfies

$$
\left|\arg \left(\frac{z f^{\prime}(z)}{f(z)}-\alpha\right)\right|<\frac{\pi}{2} \beta \quad(z \in \mathcal{U})
$$

for some $\alpha(0 \leq \alpha<1)$ and $\beta(0<\beta \leq 1)$. If $f(z) \in \mathscr{A}$ satisfies

$$
\left|\arg \left(1+\frac{z f^{\prime \prime}(z)}{f^{\prime}(z)}-\alpha\right)\right|<\frac{\pi}{2} \beta \quad(z \in \mathcal{u})
$$

for some $\alpha(0 \leq \alpha<1)$ and $\beta(0<\beta \leq 1)$, then we say that $f(z)$ is strongly convex of order $\beta$ and type $\alpha$ in $\mathcal{U}$, and we denote by $\overline{\mathscr{C}}_{\alpha}(\beta)$ the class of all such functions (see also Srivastava and Owa [16]). For the class $\mathscr{S}$ of analytic univalent functions, FeketeSzegö [6] obtained the maximum value of $\left|a_{3}-\mu a_{2}^{2}\right|$ when $\mu$ is real. For various functions of $\mathscr{S}$, the upper bound for $\left|a_{3}-\mu a_{2}^{2}\right|$ is investigated by many different authors including $[1,2,3,4,5,7,10,11,12,13,14,17]$.

In this paper, we obtain sharp upper bounds for $\left|a_{3}-\mu a_{2}^{2}\right|$ when $f$ belonging to the classes of functions defined as follows.

Definition 1.1. Let $0 \leq \alpha<1, \beta>0$ and let $f \in \mathcal{A}$. Then $f \in \mathcal{M}(\alpha, \beta)$ if and only if there exist $g \in \overline{\mathscr{Y}}_{\alpha}^{*}(\beta)$ such that

$$
\operatorname{Re}\left(\frac{z f^{\prime}(z)}{g(z)}\right)>0 \quad(z \in \mathcal{U}),
$$

and $f \in \mathscr{G}(\alpha, \beta)$ if and only if there exists $g \in \overline{\mathscr{C}}_{\alpha}(\beta)$ and satisfy condition (1.4) with $g(z)=z+b_{2} z^{2}+b_{3} z^{3}+\cdots$. 
Note that $M(0, \beta)=\mathscr{K}(\beta)$ is the class of close-to-convex functions defined in [3] and $\mathcal{M}(0,1)=\mathscr{K}(1)$ is the class of normalized close-to-convex functions defined by Kaplan [9].

2. Main results. In order to derive our main results, we have to recall here the following lemma [15].

LEMMA 2.1. Let $h \in \mathscr{P}$, that is, $h$ be analytic in $u$ and be given by $h(z)=1+c_{1} z+$ $c_{2} z^{2}+c_{3} z^{3}+\cdots$, and $\operatorname{Re} h(z)>0$ for $z \in \mathcal{U}$, then

$$
\left|c_{2}-\frac{c_{1}^{2}}{2}\right| \leq 2-\frac{\left|c_{1}^{2}\right|}{2} .
$$

THEOREM 2.2. Let $f(z) \in M(\alpha, \beta)$ and be given by (1.1). Then for $0 \leq \alpha<1, \beta \geq 1$, and $\mu \geq 1$ we have the sharp inequality

$$
\left|a_{3}-\mu a_{2}^{2}\right| \leq \frac{2 \beta^{2}(\mu-1)+\alpha \beta^{2}(8-2 \alpha-3 \mu)}{(1-\alpha)^{2}(2-\alpha)}+\frac{(2 \beta+1-\alpha)(3 \mu-2)}{3(1-\alpha)} .
$$

Proof. Let $f(z) \in M(\alpha, \beta)$. It follows from (1.4) that

$$
z f^{\prime}(z)=g(z) q(z)
$$

for $z \in \mathcal{U}$, with $q \in \mathscr{P}$ given by $q(z)=1+q_{1} z+q_{2} z^{2}+q_{3} z^{3}+\cdots$. Equating coefficients, we obtain

$$
2 a_{2}=q_{1}+b_{2}, \quad 3 a_{3}=q_{2}+b_{2} q_{1}+b_{3} .
$$

Also, it follows from (1.2) that

$$
z g^{\prime}(z)-\alpha g(z)=g(z)(p(z))^{\beta},
$$

where $z \in \mathcal{U}, p \in \mathscr{P}$, and $p(z)=1+p_{1} z+p_{2} z^{2}+p_{3} z^{3}+\cdots$. Thus equating coefficients, we obtain

$$
(1-\alpha) b_{2}=\beta p_{1}, \quad(2-\alpha) b_{3}=\beta\left(p_{2}+\frac{\beta(3-\alpha)+\alpha-1}{2(1-\alpha)} p_{1}^{2}\right)
$$

From (2.4) and (2.6), we have

$$
\begin{aligned}
a_{3}-\mu a_{2}^{2}= & \frac{1}{3}\left(q_{2}-\frac{1}{2} q_{1}^{2}\right)+\frac{2-3 \mu}{12} q_{1}^{2}+\frac{\beta}{3(2-\alpha)}\left(p_{2}-\frac{1}{2} p_{1}^{2}\right) \\
& +\frac{\beta^{2}[6(1-\mu)+\alpha(2 \alpha+3 \mu-8)]}{12(1-\alpha)^{2}(2-\alpha)} p_{1}^{2}+\frac{\beta(2-3 \mu)}{6(1-\alpha)} p_{1} q_{1} .
\end{aligned}
$$

Assume that $a_{3}-\mu a_{2}^{2}$ is positive. Thus we now estimate $\operatorname{Re}\left(a_{3}-\mu a_{2}^{2}\right)$, so from (2.7) and by using Lemma 2.1 and letting $p_{1}=2 r e^{i \theta}, q_{1}=2 R e^{i \phi}, 0 \leq r \leq 1,0 \leq R \leq 1$, $0 \leq \theta<2 \pi$, and $0 \leq \phi<2 \pi$, we obtain 


$$
\begin{aligned}
3 \operatorname{Re}\left(a_{3}-\mu a_{2}^{2}\right)= & \operatorname{Re}\left(q_{2}-\frac{1}{2} q_{1}^{2}\right)+\frac{2-3 \mu}{4} \operatorname{Re} q_{1}^{2}+\frac{\beta}{(2-\alpha)} \operatorname{Re}\left(p_{2}-\frac{1}{2} p_{1}^{2}\right) \\
& +\frac{\beta^{2}\left[\left(6+2 \alpha^{2}+3 \alpha \mu\right)-(6 \mu+8 \alpha)\right]}{4(1-\alpha)^{2}(2-\alpha)} \operatorname{Re} p_{1}^{2}+\frac{\beta(2-3 \mu)}{2(1-\alpha)} \operatorname{Re} p_{1} q_{1} . \\
\leq & 2\left(1-R^{2}\right)+(2-3 \mu) R^{2} \cos 2 \phi+\frac{2 \beta}{2-\alpha}\left(1-r^{2}\right) \\
& +\frac{\beta^{2}\left[\left(6+2 \alpha^{2}+3 \alpha \mu\right)-(6 \mu+8 \alpha)\right]}{(1-\alpha)^{2}(2-\alpha)} r^{2} \cos 2 \theta+\frac{2 \beta(2-3 \mu)}{1-\alpha} r R \cos (\theta+\phi) \\
\leq & (3 \mu-4) R^{2}+\frac{2 \beta(3 \mu-2)}{1-\alpha} r R \\
& +\frac{6 \beta^{2}(\mu-1)+\alpha \beta^{2}(8-2 \alpha-3 \mu)-2 \beta(1-\alpha)^{2}}{(1-\alpha)^{2}(2-\alpha)} r^{2}+\frac{2(\beta-\alpha)+4}{2-\alpha} \\
= & \Psi(r, R) .
\end{aligned}
$$

Letting $\alpha, \beta$, and $\mu$ fixed and differentiating $\Psi(r, R)$ partially when $0 \leq \alpha<1, \beta \geq 1$, and $\mu \geq 1$, we observe that

$$
\begin{aligned}
\Psi_{r r} \Psi_{R R}-\left(\Psi_{r R}\right)^{2}= & 4 \beta[4 \beta+2+\alpha(2 \alpha \beta+2 \alpha-4-7 \beta)] \\
& -3 \beta \mu[6 \beta+2+\alpha(2 \alpha \beta+2 \alpha-4-8 \beta)]<0 .
\end{aligned}
$$

Therefore, the maximum of $\Psi(r, R)$ occurs on the boundaries. Thus the desired inequality follows by observing that

$$
\Psi(r, R) \leq \Psi(1,1)=\frac{6 \beta^{2}(\mu-1)+\alpha \beta^{2}(8-2 \alpha-3 \mu)}{(1-\alpha)^{2}(2-\alpha)}+\frac{(2 \beta+1-\alpha)(3 \mu-2)}{1-\alpha} .
$$

The equality for (2.2) is attained when $p_{1}=q_{1}=2 i$ and $q_{1}=q_{2}=-2$.

Letting $\alpha=0$ in Theorem 2.2, we have the result given by Jahangiri [8].

COROLLARY 2.3. Let $f(z) \in \mathscr{K}(\beta)$ and be given by (1.1). Then for $\beta \geq 1$, and $\mu \geq 1$, we have the sharp inequality

$$
\left|a_{3}-\mu a_{2}^{2}\right| \leq \beta^{2}(\mu-1)+\frac{(2 \beta+1)(3 \mu-2)}{3} .
$$

THEOREM 2.4. Let $f(z) \in \mathscr{G}(\alpha, \beta)$ and be given by (1.1). Then for $0 \leq \alpha<1, \beta \geq 1$, and $\mu \geq 1$, we have the sharp inequality

$$
\left|a_{3}-\mu a_{2}^{2}\right| \leq \frac{6 \beta^{2}(3 \mu-4)+\alpha \beta^{2}(32-8 \alpha-9 \mu)}{36(1-\alpha)^{2}(2-\alpha)}+\frac{(\beta+1-\alpha)(3 \mu-2)}{3(1-\alpha)} .
$$

Proof. Let $f(z) \in \mathscr{G}(\alpha, \beta)$. It follows from (1.3) that

$$
z g^{\prime \prime}(z)+(1-\alpha) g^{\prime}(z)=g^{\prime}(z)(p(z))^{\beta},
$$

where $z \in \mathcal{U}, p \in \mathscr{P}$, and $p(z)=1+p_{1} z+p_{2} z^{2}+p_{3} z^{3}+\cdots$. Thus equating coefficients, we obtain

$$
2(1-\alpha) b_{2}=\beta p_{1}, \quad 3(2-\alpha) b_{3}=\beta\left(p_{2}+\frac{\beta(3-\alpha)+\alpha-1}{2(1-\alpha)} p_{1}^{2}\right) .
$$


From (2.4) and (2.14) and proceeding as in the proof of Theorem 2.2, we get

$$
\begin{aligned}
3 \operatorname{Re}\left(a_{3}-\mu a_{2}^{2}\right) \leq & (3 \mu-4) R^{2}+\frac{\beta(3 \mu-2)}{1-\alpha} r R+\frac{2(\beta-3 \alpha)+12}{3(2-\alpha)} \\
& +\frac{6 \beta^{2}(3 \mu-4)+\alpha \beta^{2}(32-8 \alpha-9 \mu)-8 \beta(1-\alpha)^{2}}{12(1-\alpha)^{2}(2-\alpha)} r^{2} \\
= & \Phi(r, R) .
\end{aligned}
$$

Letting $\alpha, \beta$ and $\mu$ fixed and differentiating $\Phi(r, R)$ partially when $0 \leq \alpha<1, \beta \geq 1$, and $\mu \geq 1$, we have

$$
\begin{aligned}
\Phi_{r r} \Phi_{R R}-\left(\Phi_{r R}\right)^{2}= & 4 \beta[18 \beta+8+\alpha(8 \alpha \beta+8 \alpha-16-29 \beta)] \\
& -3 \beta \mu[24 \beta+8+\alpha(8 \alpha \beta+8 \alpha-16-32 \beta)]<0 .
\end{aligned}
$$

Therefore, the maximum of $\Phi(r, R)$ occurs on the boundaries. Thus the desired inequality (2.12) follows by observing that

$$
\Phi(r, R) \leq \Phi(1,1)=\frac{6 \beta^{2}(3 \mu-4)+\alpha \beta^{2}(32-8 \alpha-9 \mu)}{12(1-\alpha)^{2}(2-\alpha)}+\frac{(\beta+1-\alpha)(3 \mu-2)}{1-\alpha} .
$$

The equality in (2.12) is attained on choosing $p_{1}=q_{1}=2 i$ and $q_{1}=q_{2}=-2$. This completes the proof of Theorem 2.4.

COROLlary 2.5. Let $f(z) \in \mathscr{G}(0, \beta)$ and be given by (1.1). Then for $\beta \geq 1$, and $\mu \geq 1$, we have the sharp inequality

$$
\left|a_{3}-\mu a_{2}^{2}\right| \leq \frac{1}{12}\left[(3 \mu-2)(\beta+2)^{2}-2 \beta^{2}\right]
$$

\section{REFERENCES}

[1] H. R. Abdel-Gawad and D. K. Thomas, A subclass of close-to-convex functions, Publ. Inst. Math. (Beograd) (N.S.) 49(63) (1991), 61-66. MR 92i:30008. Zbl 736.30007.

[2] , The Fekete-Szegö problem for strongly close-to-convex functions, Proc. Amer. Math. Soc. 114 (1992), no. 2, 345-349. MR 92e:30004. Zbl 741.30008.

[3] A. Chonweerayoot, D. K. Thomas, and W. Upakarnitikaset, On the coefficients of close-to-convex functions, Math. Japon. 36 (1991), no. 5, 819-826. MR 92j:30010. Zbl 764.30010.

[4] M. Darus and D. K. Thomas, On the Fekete-Szegö theorem for close-to-convex functions, Math. Japon. 44 (1996), no. 3, 507-511. MR 97i:30012. Zbl 868.30015.

[5] __ On the Fekete-Szegö theorem for close-to-convex functions, Math. Japon. 47 (1998), no. 1, 125-132. MR 99c:30015. Zbl 922.30009.

[6] M. Fekete-Szegö, Eine Bemerkung über ungrade Schlicht Funktionen, J. London Math. Soc. 8 (1933), 85-89 (German).

[7] R. M. Goel and B. S. Mehrok, A coefficient inequality for certain classes of analytic functions, Tamkang J. Math. 22 (1991), no. 2, 153-163. MR 92m:30019. Zbl 731.30010.

[8] M. Jahangiri, A coefficient inequality for a class of close-to-convex functions, Math. Japon. 41 (1995), no. 3, 557-559. MR 96b:30045. Zbl 832.30007.

[9] W. Kaplan, Close-to-convex schlicht functions, Michigan Math. J. 1 (1952), 169-185 (1953). MR 14,966e. Zbl 048.31101.

[10] F. R. Keogh and E. P. Merkes, A coefficient inequality for certain classes of analytic functions, Proc. Amer. Math. Soc. 20 (1969), 8-12. MR 38\#1249. Zbl 165.09102. 
[11] W. Koepf, On the Fekete-Szegö problem for close-to-convex functions, Proc. Amer. Math. Soc. 101 (1987), no. 1, 89-95. MR 88i:30015. Zbl 635.30019.

[12] _ On the Fekete-Szegö problem for close-to-convex functions. II, Arch. Math. (Basel) 49 (1987), no. 5, 420-433. MR 89a:30005. Zbl 635.30020.

[13] R. R. London, Fekete-Szegö inequalities for close-to-convex functions, Proc. Amer. Math. Soc. 117 (1993), no. 4, 947-950. MR 93e:30029. Zbl 771.30007.

[14] M. A. Nasr and H. R. El-Gawad, On the Fekete-Szegö problem for close-to-convex functions of order $\rho$, New Trends in Geometric Function Theory and Applications (Madras, 1990), World Sci. Publishing, River Edge, NJ, 1991, pp. 66-74. MR 93g:30020. Zbl 749.30005 .

[15] C. Pommerenke, Univalent Functions, With a chapter on quadratic differentials by Gerd Jensen. Studia Mathematica/Mathematische Lehrbucher, Band XXV, Vandenhoeck \& Ruprecht, Göttingen, 1975. MR 58\#22526. Zbl 298.30014.

[16] H. M. Srivastava and S. Owa (eds.), Current Topics in Analytic Function Theory, World Scientific Publishing Co., Inc., River Edge, NJ, 1992. MR 94b:30001. Zbl 970.22308.

[17] S. Y. Trimble, A coefficient inequality for convex univalent functions, Proc. Amer. Math. Soc. 48 (1975), 266-267. MR 50\#7504. Zbl 293.30014.

B. A. Frasin: School of Mathematical Sciences, Faculty of Sciences and Technology, UNIVERSITY KebANGSAAN MALAYSIA, BANGi 43600 SELANGOR, MALAYSIA

Maslina Darus: School of Mathematical Sciences, Faculty of SCiences and TeChNOLOGY, UNIVERSITY KeBANGSAAN MALAYSIA, BANGi 43600 SELANGOR, MALAYSIA

E-mail address: mas 1 ina@pkrisc.cc.ukm.my 


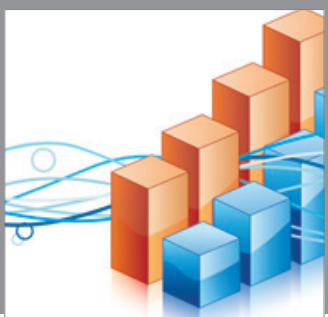

Advances in

Operations Research

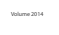

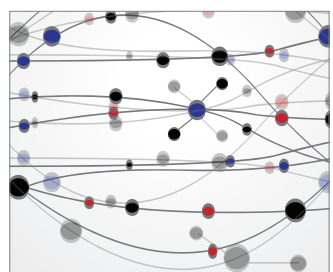

\section{The Scientific} World Journal
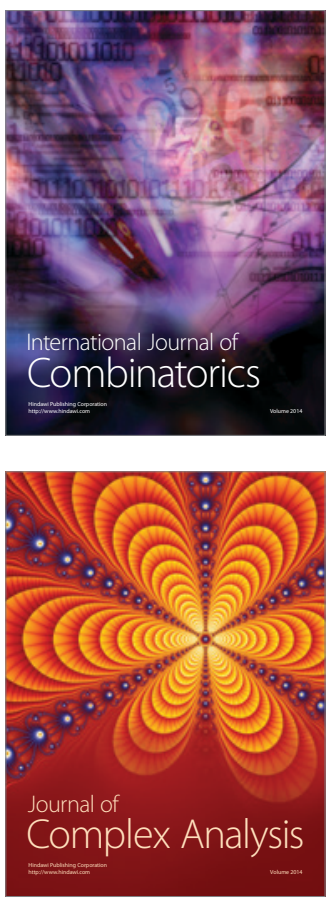

International Journal of

Mathematics and

Mathematical

Sciences
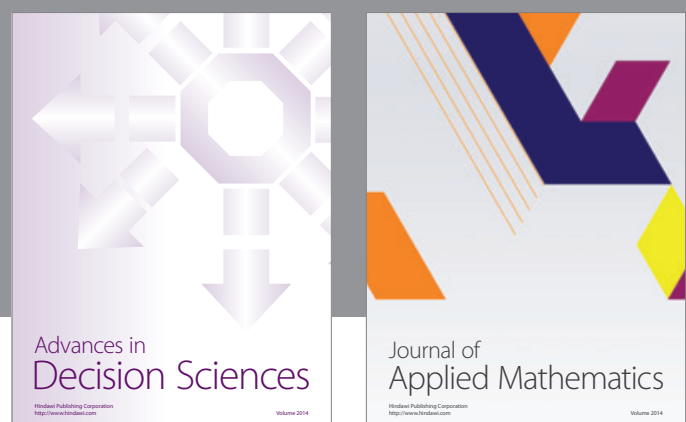

Journal of

Applied Mathematics
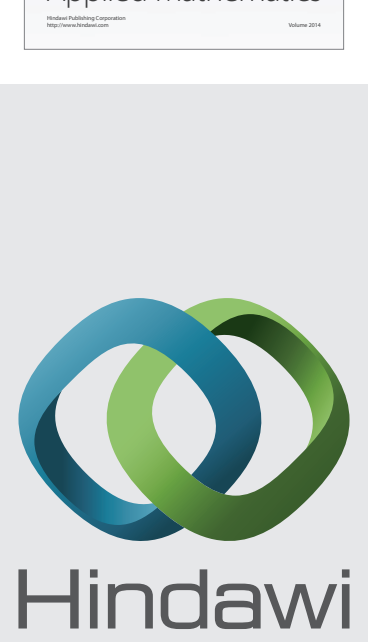

Submit your manuscripts at http://www.hindawi.com
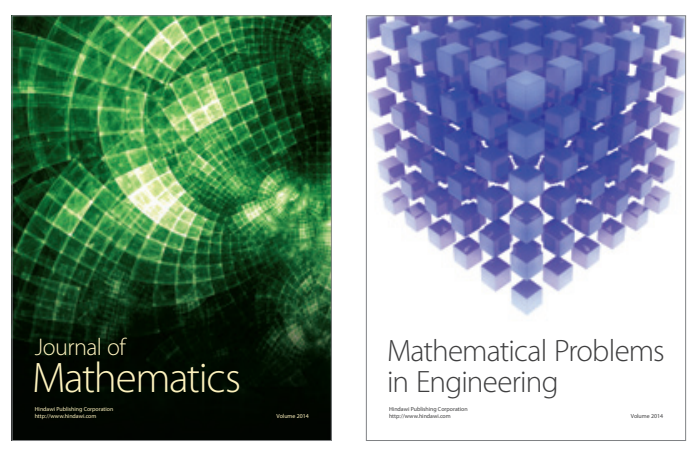

Mathematical Problems in Engineering
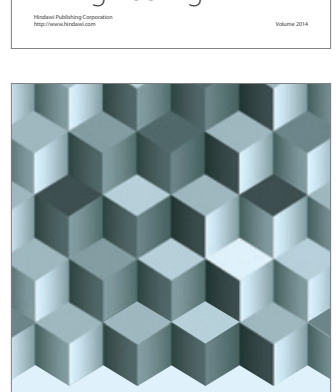

Journal of

Function Spaces
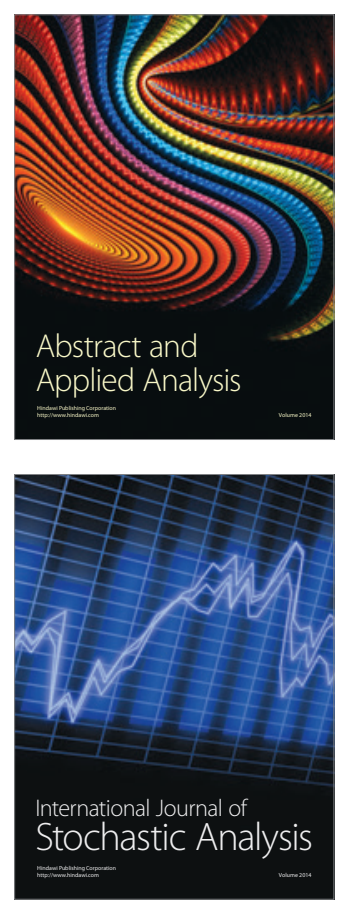

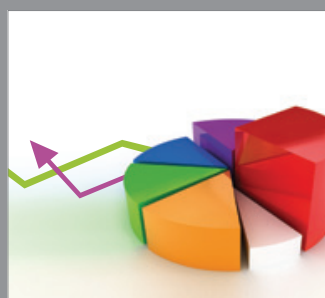

ournal of

Probability and Statistics

Promensencen
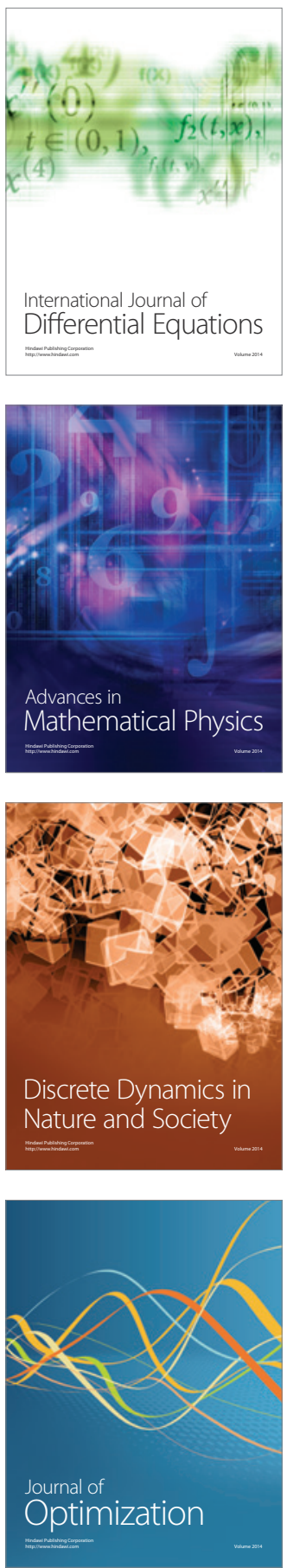